\title{
肿瘤患者、非肿㾇患者和正常人血清的 核磁共振研究
}

\author{
徐广智 李立林 陈邦钦 陈德俊 蒋大智 \\ (中国科学院化学研究所) \\ 林克㖺 卢翻苏 邓国俆光偝 \\ （北京医学院生物物理教研组）（北京市肿䘽防治研究所）
}

近年来,核磁共振用于肿瘁研究引起了广泛注意. Damadian 等曾用'H 脉冲核磁共振测定 了正常大鼠及接种 Walker 肉瘤与 Novikoff 肝癌大鼠各种组织的自旋一晶格弛予时间 $T_{1}$ 及自 旋一自旋驰予时间 $T_{2}$, 发现用 $T_{1}$ 及 $T_{2}$ 的测定值可以鉴别癌组织与正常组织 ${ }^{11}$. 其后。将此技 术用于活鼠尾部的黑色素㿔测定, 为核磁共振直接研究活体开辟了新途径 ${ }^{2-n}$ 。继之, Hollis 等又对人体各种组织作了测定,亦得到类似结果 ${ }^{[8-11]}$.

但上述研究都是以肿瘁组织为测试对象和用 $T_{1}$ 及 $T_{2}$ 的测定值为依据. 而人血清的高分

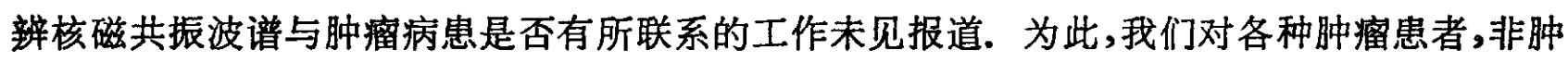
瘤患者及正常人的血清的高分辨 ${ }^{1} \mathrm{HNMR}$ 波谱进行了探讨。

\section{一、实验方法}

对患者及正常人空腹取血, 离心后取血清 $0.5 \mathrm{ml}$ 并置于样品管中, 于 $20^{\circ} \mathrm{C}$ 用 $\mathrm{RMN}-250$ 型核磁共振谱仪测 ${ }^{1}$ HNMR 谱. 样品管内放有充满 TMS 的毛细管作为测定化学位移的外 标. 'HNMR 谱中谱峰的面积用求积仪多次测量确定.

\section{二、结果 讨 论}

本文所测正常人 36 例, 各种恶性肿瘤患者 177 例、良性肿㿔患者 20 例及其它病患者 42 例血清的 ${ }^{1} \mathrm{HNMR}$ 谱都基本相似,其高场部分如图 1 所示, 在化学位移为 $1.0 、 0.6$ 及 $1.8 \mathrm{ppm}$ 处 有分别标志为 $\alpha 、 \beta$ 及 $\gamma$ 的三个峰. 为寻求它们之区别, 先以 $\alpha$ 及 $\beta$ 峰的高度比 $h_{\alpha} / h_{\beta}$ 为对比 指标, 则肿㿔患者与正常人之间虽有差异, 但不理想. 若采用 $\alpha$ 及 $\beta$ 峰的面积比 $S_{\alpha}^{*} / S_{\beta}$ 进行对 比, 则多数肿瘤患者与正常人之间似有一定的规律性. 所得结果分别列于表 1一表 4. 正常人 36 例、恶性肿瘤患者 177 例、良性肿㿔患者 20 例及其它病患者的 $S_{\alpha} / S_{\beta}$ 之平均值分别为 1.85 、 $2.42 、 2.87$ 及 2.03 .

从这些数据可以看出:

1. 5 例以上的癌患者, 除膀胱癌外, 其余的 $S_{\alpha} / S_{\beta}$ 值与正常人的对比, 均有明显差异. 特 别是 9 例以上的官颈癌等七种癌的 $P$ 值都小于 0.001 , 差异突出.

本文 1980 年 11 月 8 日收到. 
2. 5 例以下的癌患者中绝大多数之 $S_{\alpha} / S_{\beta}$ 值也大于 2 ; 但何杰金氏病、脂肪肉瘤、腃腺癌、 精原细胞瘤及瓦特氏蕜腹癌等之 $S_{\alpha} / S_{\beta}$ 值则较小,难以看出与正常人的不同.

3. 20 例良性肿瘤患者之 $S_{\alpha} / S_{\beta}$ 值都远大于 2 , 只有甲状腺㿔例外, 其平均值与正常人的 比较, $P$ 小于 0.001 , 有显著差异.

4. 从 $S_{\alpha} / S_{\beta}$ 值难以将良性肿瘤与恶性肿瘤 彼此区分. 但注意到甲状腺癌之 $S_{\alpha} / S_{\beta}$ 值为 2.03 , 甲状腺㾇的,为 1.49 ; 乳腺癌、乳腺瘤与乳房包块 之 $S_{\alpha} / S_{\beta}$ 值分别为 $2.43 、 2.23$ 及 1.95 ; 有逐渐减少 的趋势是有趣的.

5. 其它病患者的测定结果比较复杂, 其 $S_{\alpha} /$ $S_{\beta}$ 的平均值与正常人的接近. 不过某些病患者之 $S_{\alpha} / S_{\beta}$ 则明显高于正常人,如肝炎、肺炎、宫颈炎等 即其例.

6. 同一器官的恶性肿瘤之 $S_{\alpha} / S_{\beta}$ 值有大于 其它病患的趋势. 如 9 例肝癌的平均值 2.52 比 7

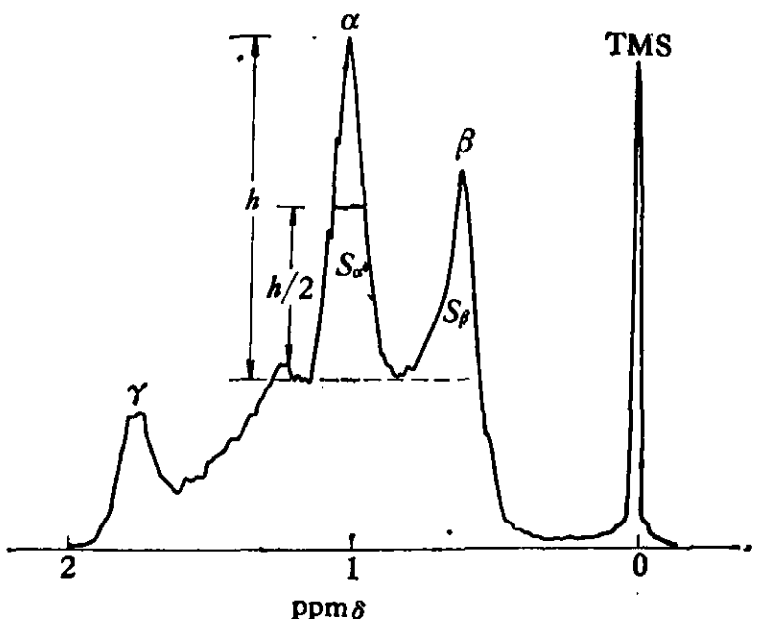

图 1 血清 'HNMS 的高场部分 例肝硬变的平均值 1.84 为大. 胃癌之值比胃溃病、胃炎等的为大. 宫颈癌及肺癌之值也分别 表 15 例以上各种癌患者测定结果

\begin{tabular}{|c|c|c|c|c|c|}
\hline 病 & 名 & 例 数 & $S_{a} / S_{\beta}$ & 标准误差 & $\begin{array}{l}\text { 与正常人相比 } \\
\text { 较之 } P \text { 值 }\end{array}$ \\
\hline 官 颈 & 癌 & 23 & 2.52 & \pm 0.14 & $<0.001$ \\
\hline 肺 & 癌 & 21 & 2.52 & \pm 0.12 & $<0.001$ \\
\hline 周 & 癌 & 19 & 2.52 & \pm 0.10 & $<0.001$ \\
\hline 食 道 & 癌 & 16 & 2.35 & \pm 0.11 & $<0.001$ \\
\hline 肠 & 癌 & 14 & 2.40 & \pm 0.17 & $<0.001$ \\
\hline 乳 腺 & 癌 & 13 & 2.43 & \pm 0.15 & $<0.001$ \\
\hline 肝 & 澢 & 9 & 2.52 & \pm 0.15 & $<0.001$ \\
\hline 搌 & 獣 & 6 & 2.63 & \pm 0.25 & $<0.002$ \\
\hline 星形细胞 & & 5 & 2.74 & \pm 0.25 & $<0.001$ \\
\hline 脖 睄 & 癌 & 5 & 1.84 & \pm 0.10 & $>0.05$ \\
\hline
\end{tabular}

表 25 例以下癌患者的测定结果

\begin{tabular}{|c|c|c|c|c|c|}
\hline 病名 & 例 数 & $S_{\alpha} / S_{\beta}$ & 病 名 & 例 数 & $S_{\alpha} / S_{\beta}$ \\
\hline 淋巴肉瘟 & 3 & 2.53 & 线癌 & 1 & 3.14 \\
\hline 卵巢瘦 & 4 & 2.04 & 軎体瘦 & 1 & 2.46 \\
\hline 白血病 & 4 & 2.36 & 阴茎癌 & 1 & 2.42 \\
\hline 畸胎痹葡萄胎 & 3 & 2.50 & 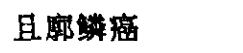 & 1 & 3.75 \\
\hline 㫷咽癌 & 3 & 2.63 & 胸腺癌 & 1 & 2.64 \\
\hline 何杰金氏病 & 3 & 1.90 & 㓞带透明细胞癌 & 1 & 2.29 \\
\hline 胆管癌 & 2 & 3.21 & 顾内结核㿔 & 1 & 2.22 \\
\hline 肾䆓 & 2 & 2.79 & 黑色素瘤 & 1 & 2.13 \\
\hline 上领晏癌 & 2 & 2.76 & 骨涟瘤 & 1 & 2.22 \\
\hline 滑膜肉溜 & 2 & 2.50 & 脂肪肉瘤 & 1 & 1.89 \\
\hline 纤维肉瘦 & 2 & 2.17 & 胰腺瘦 & 1 & 1.67 \\
\hline 甲状腺痹 & 2 & 2.03 & 精原细胞瘤 & 1 & 1.81 \\
\hline 外阴癌 & 1 & 4.32 & 瓦特氏壸腹癌 & 1 & 1.81 \\
\hline
\end{tabular}


大于官颈炎及气管炎之值.

表 3 良性肿瘤患者的测定结果

\begin{tabular}{|c|c|c|c|c|c|}
\hline 病名 & 例 数 & $s_{a} / S_{\beta}$ & 病名 & 例 数 & $S_{\alpha} / S_{\phi \beta}$ \\
\hline 头部肿物 & 4 & 2.43 & 乳腺政 & 1 & 2.23 \\
\hline 卵监肿物 & 4 & 2.76 & 垂体腺㾇 & 1 & 3.80 \\
\hline 子官肌童 & 3 & 3.19 & 肺纤维离 & 1 & 2.41 \\
\hline 膜离 & 3 & 3.00 & 胃息肉 & 1 & 5.32 \\
\hline 听神经瘦 & 1 & 2.78 & 甲状腺溜 & 1 & 1.49 \\
\hline
\end{tabular}

表 4 非肿瘤患者的测定结果

\begin{tabular}{|c|c|c|c|c|c|}
\hline 病名 & 例 数 & $S_{a} / S_{\beta}$ & 病名 & 例 数 & $S_{\alpha} / S_{\beta}$ \\
\hline 周炎、胃溃疡 & 8 & 1.95 & 肺炎 & 1 & 2.47 \\
\hline 肝硬变 & 7 & 1.84 & 肺结核 & 2 & 1.89 \\
\hline 气管炎 & 5 & 1.83 & 附件炎性包块 & 1 & 1.92 \\
\hline 官颈次 & 3 & 2.15 & 慢性菌莉 & 1 & 1.24 \\
\hline 肝炎 & 3 & 2.33 & 多意肝 & 1 & 1.56 \\
\hline 乳房包块 & 2 & 1.95 & 子官肌腺病 & 1 & 2.77 \\
\hline 甲状腺肿 & 2 & 2.46 & 腹腔结核肿块 & 1 & 2.25 \\
\hline 淋巴结核 & 2 & 2.32 & 结核性胸膜炎 & 1 & 1.85 \\
\hline 肺事肿 & 1 & 2.73 & 输尿管炎店 & 1 & 2.14 \\
\hline
\end{tabular}

\section{考文竍}

i1] Damadian, R. et al., Science, 171(1971), 1151.

[2] Iijima et al., Japan. Electron Optias Lab. News, 9a(1972), 5.

[ 3 ] Hollis, D. P. et al., Johns Hopkins Med. J., 131(1972), 441.

[ 4 ] Frey, H. E. et al., J. Natl. Cancer Inst., 49(1972), 903.

[ 5 ] Hazlewood, C. F. et al., Proc. Natl. Acad. Sci. U. S. A., 69(1972), 1478.

[. 6 ] Floyd, R. A. et al., Cancer Research, 34(1974), 89.

[ 7 ] Weigman, I. D. et al., Science, 178(1972), 1288.

[ 8 ] Hollis, D. P. et al., Cancer Research, 33(1973), 2156.

[9] Damadian, R. et al., Physiol. Chem. Physics, 5(1973), 381.

[10] Eggleston, J. C. et al., Cancer Research, 35(1973), 1326.

[11] Medina, D. et al., J. Natl. Cancer Inst., 54(1975), 813. 